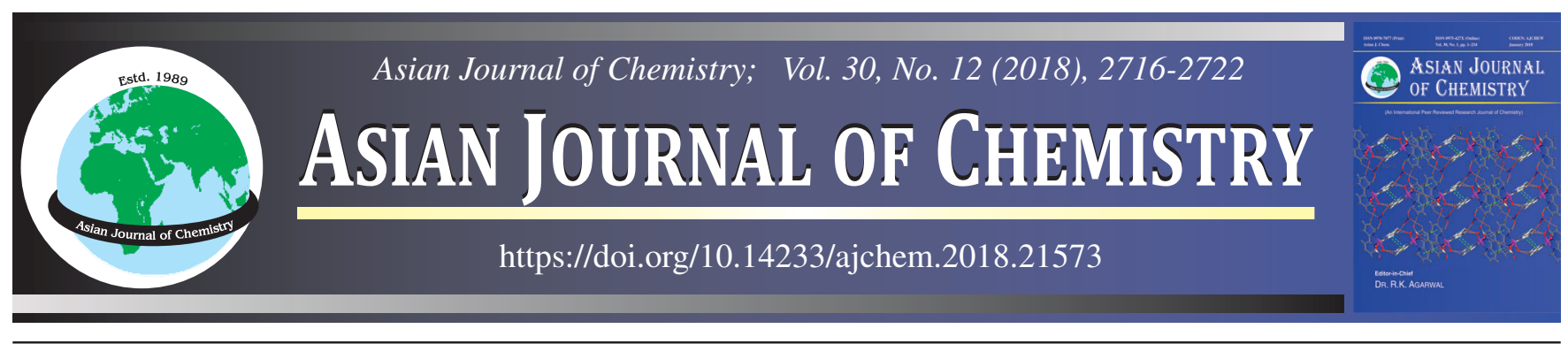

\title{
Determination of Various Properties of Ethyl Actetate $+n$-Butanol Binary Mixture at Different Temperatures
}

\author{
SoUJANYA KAKI ${ }^{1, *}$ and D. RAMA CHANDRAN ${ }^{2}$
}

${ }^{1}$ Department of Chemistry, CMR College of Engineering \& Technology (Autonomous), Hyderabad-501 401, India

${ }^{2}$ Department of Chemistry, Acharya Nagarjuna University, Guntur-522 510, India

*Corresponding author: E-mail: soujanya.kaki@gmail.com

Received: 11 July 2018;

Accepted: 30 September 2018;

Published online: 31 October 2018;

AJC-19137

The present study deals with the variations of ultrasonic velocity, density, viscosity, various acoustic and thermodynamic parameters such as adiabatic compressibility, intermolecular free length, molar volume, acoustic impedance, free volume, internal pressure, enthalpy and also excess thermodynamic properties for $n$-butanol with ethyl acetate as function of concentration and temperature. All the excess parameters are fitted into the Redlich-Kister equation. And also to compare the ultrasonic sound velocity in ethyl acetate with $n$-butanol mixture from various theoretical relations of Nomoto and Van Dael Vangeel. These properties can be effectively utilized as a qualitative study to predict the extent of molecular interactions between the components.

Keywords: Intermolecular forces, Ethyl actetate, $\boldsymbol{n}$-Butanol, Binary mixture, Nomoto, Van Dael and Vangeel.

ᄂ _ _ - - - - - - - - - - - - - - - - - - - - - - - - - - -

\section{INTRODUCTION}

In recent years, the study of thermodynamic properties of binary mixtures and ternary mixtures has grown significantly. The thermodynamic properties of liquids in any binary mixture depict substantial weight on the physical and chemical properties [1-5]. These properties provide better information necessary for understanding the non -ideal behaviour of complex systems, that are caused by molecular interactions, dipole-dipole interactions etc. of different molecules. In practical world, these properties are very much needed in diverse areas like bio-chemical, food industry, metallurgy, molecular dynamics studies and others .Added to it, information about structural phenomena of these mixtures also provides first-hand material in the development of theories of the liquid state interactions.

The excess thermodynamic properties proposed by Scatchard in the year 1931, paved a path that how a solution deviates from its ideal behaviour. He proposed an equation to calculate the excess thermodynamic parameters which is shown below, where excess thermodynamic parameters denoted by super script E.

$$
\mathrm{Y}^{\mathrm{E}}=\mathrm{Y}_{\text {real }}^{\mathrm{M}}-\mathrm{Y}_{\text {ideal }}^{\mathrm{M}}
$$

van der Waals and Van Laar [6] proposed the initial theories of binary liquid mixtures. These theories successfully explained certain excess properties in the critical region of liquid mixtures. In an attempt to improve Van Laar's theory, Hildebrand and Scott [7] and Scatchard [8] used Hildebrand's [9-12] concept of regular solutions to formulate a relation for excess volume.

Redlich and Kister [13] derived an experimental equation to predict $\mathrm{Y}^{\mathrm{E}}$ values for binary liquid mixtures.

$$
\mathrm{Y}^{\mathrm{E}}=\mathrm{X}_{1} \mathrm{X}_{2}\left[\mathrm{~A}_{0}+\mathrm{A}_{1}\left(\mathrm{X}_{1}-\mathrm{X}_{2}\right)+\mathrm{A}_{2}\left(\mathrm{X}_{1}-\mathrm{X}_{2}\right)\right]
$$

where $A_{0}, A_{1}$ and $A_{2}$ are constants $X_{1}, X_{2}$ are the mole fractions of the two different components. Rao [14] found that the thermal coefficient of ultrasonic velocity in organic liquids is about three times the thermal coefficient of density.

$$
\mathrm{R}=\mathrm{U}^{1 / 3} \mathrm{~V}
$$

where $\mathrm{R}$ is known as molar sound velocity constant

Jacobson [15] derived an empirical relation between three thermodynamic parameters (ultrasonic velocity, density, and intermolecular free length). The literature survey revealed a great volume of work has been carried out in binary and ternary systems of weak and strong interacting systems but few studies are reported with ethyl acetate as the main component.

This is an open access journal, and articles are distributed under the terms of the Creative Commons Attribution-NonCommercial 4.0 International (CC BY-NC 4.0) License, which allows others to copy and redistribute the material in any medium or format, remix, transform, and build upon the material, as long as appropriate credit is given and the new creations are licensed under the identical terms. 
Moreover, thermodynamic properties of these liquid mixtures are of interest for different branches of science and engineering and also play a significant role in technological processes, biological process of living organisms and in nature. A review of the literature reveals no thermodynamic studies conducted for the above liquid mixture at 303.15 and $313.15 \mathrm{~K}$. To have a precise knowledge about the molecular interactions between the component molecules, ultrasonic velocities, densities, viscosities and theoretical relations of Nomoto and Van Dael and Vangeel of ethyl acetate $+n$-butanol at the aforementioned temperatures have been studied for the entire composition range. In addition to above, the present study also provides a better insight into the nature of the molecular structure on volumetric properties and molecular interactions in the aforementioned binary system.

\section{EXPERIMENTAL}

The ultrasonic velocity measurements are made with the help of a single crystal ultrasonic pulse echo-interferometer. Number of pulses satisfying in phase condition is counted and separation between them is estimated in terms of the pulse repetition rate. The accuracy in velocity measurement is within \pm $0.02 \%$. The densities of the liquid mixture (ethyl acetate + $n$-butanol) have been determined by using a single pan electrical balance for the determination of mass of a given volume of the liquid. Weight measurements in the present study are made employing a single pan electronic balance capable of measuring up to $0.05 \mathrm{mg}$. The coefficient of viscosity has been determined as a function of composition and temperature, using Oswald's viscometer. The accuracy of viscosity measurement is $\pm 0.001 \mathrm{cp}$. The temperature of the mixture is maintained at the required constant value by using constant temperature bath, controlled by thermostat with an accuracy of $\pm 0.01 \mathrm{~K}$. All the excess parameters are fitted into the Redlich-Kister equation. The values of parameters obtained by Cramer's rule are included with the standard deviation $(\sigma)$. The excess volumes of mixing have been evaluated both as a formation of composition and temperature to examine the possibility of structural adjustment. The closer packing of molecules due to the dipole-dipole interactions between hetero molecules is bound to have greater influence on the overall compressibility of the systems.

Ethyl acetate $+n$-butanol, system has been chosen and studied its excess properties at the temperatures of 303.15 and $313.15 \mathrm{~K}$ over the entire composition range. From these measured values, the following thermodynamic and transport parameters, which are useful for understanding the nature of interaction of ethyl acetate with $n$-butanol are evaluated. The present study has been divided into three parts:

(A) Study of variation in adiabatic compressibility, molar volume, mean free length, viscosity and related parameters at 303.15 and $313.15 \mathrm{~K}$.

(B) Study of variation in free volume, internal pressure, enthalpy and Gibbs free energy of activation and their excess parameters at 303.15 and $313.15 \mathrm{~K}$.

(C) Estimating the variation of theoretical velocities using Nomoto Relation (Nom) and Van Dael Vangeel ideal mixing relation (Van) at 303.15 and $313.15 \mathrm{~K}$.

An attempt has been made to compare the merits of the relations for the binary liquid mixture investigated at different temperatures. The results are explained in terms of intermolecular interactions occurring in this binary system. The deviation in the variation of $\mathrm{U}_{\text {exp }}^{2} / \mathrm{U}^{2}$ imx from unity has also been evaluated for explaining the non-ideality in the mixture.

The data obtained can be used to understand intermolecular interactions between the unlike molecules and to test the theories of solutions. The departure of this real mixture from ideal behaviour can be explained in terms of effect of hydrogen bond breaking, loss of dipolar association, differences in size and shapes, dipole-dipole interactions between different component molecules.

\section{RESULTS AND DISCUSSION}

Study of variation in adiabatic compressibility, molar volume, mean free length, viscosity and related parameters at 303.15 and 313.15 K: The experimentally measured values of ultrasonic velocity $(\mathrm{U})$ density $(\rho)$ and viscosity $(\eta)$ of the binary mixture had been measured for the entire range of composition at two different temperatures (303.15 and 313.15 $\mathrm{K})$. The molar volume $\left(\mathrm{V}_{\mathrm{m}}\right)$, adiabatic compressibility $\left(\beta_{\mathrm{ad}}\right)$, intermolecular free length $\left(\mathrm{L}_{\mathrm{f}}\right)$, Rao's constant $(\mathrm{R})$ and Wada's constant $(\mathrm{W})$ were computed along with the measured values. The excess parameters such as excess molar volume $\left(V_{m}{ }^{\mathrm{E}}\right)$, excess intermolecular free length $\left(\mathrm{L}_{\mathrm{f}}^{\mathrm{E}}\right)$ and deviations in adiabatic compressibility $\left(\beta_{\mathrm{ad}}\right)$, deviations in viscosity $(\Delta \eta)$ and several other parameters have also been calculated and are presented in Tables 1 to 3 . The results are interpreted in terms of intermolecular interactions between the components of the mixtures.

TABLE-1

VARIATION OF $\mathrm{U}, \rho, \eta, \mathrm{V}_{\mathrm{m}}$ AT $303.15 \mathrm{~K}$ AND $313.15 \mathrm{~K}$

\begin{tabular}{|c|c|c|c|c|c|c|c|c|}
\hline \multirow{2}{*}{$\begin{array}{c}\text { Mole } \\
\text { fraction } \mathrm{X}\end{array}$} & \multicolumn{2}{|c|}{ Ultrasonic velocity $(\mathrm{U})(\mathrm{m} / \mathrm{s})$} & \multicolumn{2}{|c|}{$\rho \times 10^{-3}\left(\mathrm{~kg} / \mathrm{m}^{3}\right)$} & \multicolumn{2}{|c|}{$\eta \mathrm{Cp}$} & \multicolumn{2}{|c|}{$\mathrm{V}_{\mathrm{m}}\left(\mathrm{cm}^{-3} \mathrm{~mol}^{-1}\right)$} \\
\hline & $303.15 \mathrm{~K}$ & $313.15 \mathrm{~K}$ & $303.15 \mathrm{~K}$ & $313.15 \mathrm{~K}$ & $303.15 \mathrm{~K}$ & $313.15 \mathrm{~K}$ & $303.15 \mathrm{~K}$ & $313.15 \mathrm{~K}$ \\
\hline 0.0000 & 1222.00 & 1211.00 & 0.8033 & 0.7982 & 2.2755 & 2.0844 & 92.2694 & 92.8589 \\
\hline 0.0937 & 1211.62 & 1199.28 & 0.8213 & 0.8186 & 2.1270 & 1.9533 & 91.8447 & 92.1455 \\
\hline 0.1887 & 1201.59 & 1185.76 & 0.8387 & 0.8372 & 1.9743 & 1.8145 & 91.5191 & 91.6922 \\
\hline 0.2851 & 1192.27 & 1171.64 & 0.8547 & 0.8542 & 1.8179 & 1.6697 & 91.3828 & 91.4392 \\
\hline 0.3829 & 1182.97 & 1157.49 & 0.8688 & 0.8688 & 1.6553 & 1.5178 & 91.4760 & 91.4760 \\
\hline 0.4820 & 1173.59 & 1143.54 & 0.8799 & 0.8799 & 1.4819 & 1.3547 & 91.8988 & 91.8988 \\
\hline 0.5826 & 1163.87 & 1130.24 & 0.8852 & 0.8852 & 1.2822 & 1.1723 & 92.9416 & 92.9416 \\
\hline 0.6847 & 1152.75 & 1116.65 & 0.8878 & 0.8876 & 1.0710 & 0.9793 & 94.2744 & 94.2948 \\
\hline 0.7882 & 1141.82 & 1103.30 & 0.8881 & 0.8865 & 0.8536 & 0.7803 & 95.8796 & 96.0468 \\
\hline 0.8933 & 1129.56 & 1090.01 & 0.8884 & 0.8830 & 0.6311 & 0.5746 & 97.5037 & 98.0905 \\
\hline 1.0000 & 1115.90 & 1076.00 & 0.8886 & 0.8758 & 0.4038 & 0.3652 & 99.1560 & 100.6052 \\
\hline
\end{tabular}


TABLE-2

VARIATION OF $\beta_{\mathrm{ad}}, \mathrm{L}_{\mathrm{f}}$, R, W AT 303.15 K AND 313.15 K

\begin{tabular}{|c|c|c|c|c|c|c|c|c|}
\hline \multirow{2}{*}{$\begin{array}{c}\text { Mole } \\
\text { fraction X }\end{array}$} & \multicolumn{2}{|c|}{$\beta_{\mathrm{ad}} 10^{12} \mathrm{~m}^{2} \mathrm{~N}^{-2}$} & \multicolumn{2}{|c|}{$\mathrm{L}_{\mathrm{f}} 10^{-10} \mathrm{~m}$} & \multicolumn{2}{|c|}{$\mathrm{R}$} & \multicolumn{2}{|c|}{ W } \\
\hline & $303.15 \mathrm{~K}$ & $313.15 \mathrm{~K}$ & $303.15 \mathrm{~K}$ & $313.15 \mathrm{~K}$ & $303.15 \mathrm{~K}$ & $313.15 \mathrm{~K}$ & $303.15 \mathrm{~K}$ & $313.15 \mathrm{~K}$ \\
\hline 0.0000 & 83.3642 & 85.4280 & 0.5725 & 0.5878 & 4579 & 4594 & 2541 & 2548 \\
\hline 0.0937 & 82.9410 & 84.9343 & 0.5710 & 0.5861 & 4545 & 4544 & 2531 & 2530 \\
\hline 0.1887 & 82.5771 & 84.9580 & 0.5698 & 0.5862 & 4516 & 4505 & 2523 & 2518 \\
\hline 0.2851 & 82.3027 & 85.2795 & 0.5688 & 0.5873 & 4498 & 4474 & 2521 & 2509 \\
\hline 0.3829 & 82.2479 & 85.9091 & 0.5686 & 0.5895 & 4491 & 4458 & 2524 & 2508 \\
\hline 0.4820 & 82.5130 & 86.9073 & 0.5695 & 0.5929 & 4499 & 4461 & 2534 & 2515 \\
\hline 0.5826 & 83.3981 & 88.4345 & 0.5726 & 0.5981 & 4538 & 4494 & 2559 & 2538 \\
\hline 0.6847 & 84.7635 & 90.3511 & 0.5773 & 0.6045 & 4588 & 4541 & 2589 & 2567 \\
\hline 0.7882 & 86.3695 & 92.6674 & 0.5827 & 0.6122 & 4652 & 4607 & 2627 & 2605 \\
\hline 0.8933 & 88.2262 & 95.3140 & 0.5889 & 0.6209 & 4713 & 4686 & 2663 & 2650 \\
\hline 1.0000 & 90.3739 & 98.6213 & 0.5961 & 0.6316 & 4774 & 4785 & 2699 & 2704 \\
\hline
\end{tabular}

TABLE-3

VARIATION OF $V_{\mathrm{m}}{ }^{\mathrm{E}}, \Delta \beta_{\mathrm{ad}}, \Delta \eta \mathrm{cp}, \mathrm{L}_{\mathrm{f}}^{\mathrm{E}}$ AT $303.15 \mathrm{~K}$ AND $313.15 \mathrm{~K}$

\begin{tabular}{ccc|cc|ccc|c}
\hline \multirow{2}{*}{$\begin{array}{c}\text { Mole } \\
\text { fraction X }\end{array}$} & \multicolumn{2}{c|}{$\mathrm{V}_{\mathrm{m}}{ }^{\mathrm{E}}\left(\mathrm{cm}^{3} \mathrm{~mol}^{-1}\right)$} & \multicolumn{2}{c|}{$\Delta \beta_{\mathrm{ad}} 10^{10} \mathrm{~m}^{2} \mathrm{~N}^{-1}$} & \multicolumn{2}{c|}{$\Delta \eta \mathrm{cp}$} & \multicolumn{2}{c}{$\mathrm{L}_{\mathrm{f}}^{\mathrm{E}} 10^{-10} \mathrm{~m}$} \\
\cline { 2 - 9 } & $303.15 \mathrm{~K}$ & $313.15 \mathrm{~K}$ & $303.15 \mathrm{~K}$ & $313.15 \mathrm{~K}$ & $303.15 \mathrm{~K}$ & $313.15 \mathrm{~K}$ & $303.15 \mathrm{~K}$ & $313.15 \mathrm{~K}$ \\
\hline 0.0000 & 0.0000 & 0.0000 & 0.0000 & 0.0000 & 0.0000 & 0.0000 & 0.0000 \\
0.0937 & -1.0700 & -1.4300 & -1.0800 & -1.7300 & 0.0269 & 0.0300 & -0.0037 \\
0.1887 & -2.0500 & -2.6100 & -2.1100 & -2.9600 & 0.0520 & 0.0546 & -0.0072 \\
0.2851 & -2.8500 & -3.6000 & -3.0600 & -3.9100 & 0.0760 & 0.0755 & -0.0104 \\
0.3829 & -3.4300 & -4.3107 & -3.8000 & -4.5700 & 0.0964 & 0.0916 & -0.0000 \\
0.4820 & -3.6900 & -4.6462 & -4.2300 & -4.8800 & 0.1086 & 0.0990 & -0.0143 \\
0.5826 & -3.3400 & -4.3727 & -4.0500 & -4.6800 & 0.0972 & 0.0895 & -0.0137 \\
0.6847 & -2.7100 & -3.8000 & -3.4000 & -4.1100 & 0.0770 & 0.0720 & -0.0114 \\
0.7882 & -1.8181 & -2.8400 & -2.5200 & -3.1600 & 0.0534 & 0.0510 & -0.0151 \\
0.8933 & -0.9177 & -1.6000 & -1.4000 & -1.9000 & 0.0277 & 0.0260 & -0.0084 \\
1.0000 & 0.0000 & 0.0990 & 0.0000 & 0.0000 & 0.0000 & 0.0000 & -0.0152 \\
\end{tabular}

Ultrasonic velocity $(\mathrm{U})$ in this system is plotted with respect to mole fraction of ethyl acetate for different temperatures. The curves of ultrasonic velocity indicate that the velocity decreases non-linearly with mole fraction of ethyl acetate and the decrease in ultrasonic velocity in any solution indicates the maximum association among the molecules of the solution. The maximum association is due to dipole-dipole interactions between the solute and solvent molecules. Variation of density with mole fraction of ethyl acetate $+n$-butanol system is given in Table- 1 . The composition dependence of viscosity $(\eta)$ and deviation in viscosity $(\Delta \eta)$ are shown in Tables 1 and 3 for this mixture. The viscosity values show positive deviations maximum at about 0.48 mole fraction of ethyl acetate. These results are favouring the dipole-dipole interactions between unlike molecules in binary mixtures.

The excess volumes $\left(\mathrm{V}^{\mathrm{E}}\right)$ of mixing have been evaluated both as a formation of composition and temperature to examine the possibility of structural adjustment. The variation of molar volume $(\mathrm{V})$ and excess molar volume $\left(\mathrm{V}^{\mathrm{E}}\right)$ with mole fraction of ethyl acetate in this system is shown in Tables 1 and 3, respectively. The results indicate that there is a volume contraction in mixing. The $\mathrm{V}^{\mathrm{E}}$ values become more and more negative as the temperature is increased. The broad negative $\mathrm{V}^{\mathrm{E}}$ is observed at about 0.48 mole fraction of ethyl acetate.

Variation of adiabatic compressibility $\left(\beta_{\mathrm{ad}}\right)$ and deviation in adiabatic compressibility $\left(\Delta \beta_{\text {ad }}\right)$ plotted against the mole fraction of ethyl acetate in the binary system for the different temperatures of study are shown in Tables 2 and 3. It can be seen that the deviation in adiabatic compressibility $\left(\Delta \beta_{\mathrm{ad}}\right)$ is negative over the entire composition range reaching broad minimum at about 0.48 mole fraction of ethyl acetate. The effect of temperature on the compressibility curves is in agreement with the idea that interaction between unlike molecules predominantly rupture the hydrogen-bonded structures, which is the main cause of deviation in adiabatic compressibility.

The structural changes are also found to influence the variation of intermolecular free length. In fact, when the liquid mixture assumes a less compressible phase of decreased flow capacity as evidenced by $\Delta \beta_{\text {ad }}$ versus composition curves and $\eta$ versus composition curves, the intermolecular free length might also be affected by the same structural changes. Variation of intermolecular free length $\left(\mathrm{L}_{\mathrm{f}}\right)$ and excess intermolecular free length $\left(\mathrm{L}_{\mathrm{f}}^{\mathrm{E}}\right)$ is plotted with the composition of ethyl acetate in mixture is shown in Tables 2 and 3. These curves indicated that the intermolecular free length varies non-linearly with mole fraction and increases slightly with increase in temperature.

The molar sound velocity $(\mathrm{R})$ and molar compressibility (W) are the two important parameters, which are widely used for the study of physico-chemical behaviour of liquid and liquid mixtures. The parameters (R) and (W) are also called Rao's constant and Wada's constant, respectively. For many liquid mixtures, Rao's empirical relation has been extensively used and verified by number of workers [16,17]. Molar compressibility (W) is found to be useful in understanding molecular interactions and structures of pure liquids and their solutions. The variation of Rao's constant and Wada's constant [18] with composition of ethyl acetate is given in Table-2. In can be seen that there is a linearity of these constants at all the temper- 
atures. Further, over the temperature range 303.15 to $313.15 \mathrm{~K}$, the variations of these constants are almost negligible at any particular mole fraction. These results are favouring the dipoledipole interactions between unlike molecules in binary mixtures.

The excess values $\left(\mathrm{V}^{\mathrm{E}}, \mathrm{L}_{\mathrm{f}}^{\mathrm{E}}, \beta_{\mathrm{ad}}\right.$ and $\left.\Delta \eta\right)$ are fitted in to an empirical equation of the form:

$$
A^{E}=X_{1} X_{2}\left[A+B\left(X_{1}-X_{2}\right)+C\left(X_{1}-X_{2}\right)^{2}\right]
$$

where $\mathrm{A}^{\mathrm{E}}$ is the excess parameter, $\mathrm{X}_{1}$ and $\mathrm{X}_{2}$ are the mole fraction of the two components. The coefficients $\mathrm{A}, \mathrm{B}$ and $\mathrm{C}$ evaluated form linear least square method are given in Tables. The standard deviations of (AE) are evaluated by the following relation:

$$
\sigma\left(A^{E}\right)=\frac{\Sigma\left(A_{e x p}^{E}-A_{e q}^{E}\right)}{(m-n)^{1 / 2}}
$$

where $\mathrm{m}$ is number of experimental data and $\mathrm{n}$ is the number of coefficients.

The results of the excess values indicate that the agreement between the experimental and theoretical values of the excess values is in satisfactory agreement (Tables 4 and 5).
Study of variation in free volume, internal pressure, enthalpy and Gibbs free energy of activation and their excess parameters at 303.15 and 313.15 K: In order to substantiate the presence of interaction between the molecules, it is essential to study the excess parameters like free volume, internal pressure and enthalpy. The deviation of physical property of the liquid mixtures from the ideal behavior is a measure of the interaction between the molecules, which is attributed to either adhesive or cohesive forces [18].

Free volume $\left(\mathbf{V}_{\mathbf{f}}\right)$ : Hirschfelder $[19,20]$ found that free volume of a solute molecule at a particular temperature and pressure depends only on the internal pressure of the liquid in which it is immersed. The weakening of molecular association leads to a larger free volume available for molecular motion and the reverse effect gives rise to smaller free volume. Table-4 shows the variation of free volume in the binary system at two different temperatures.

Internal pressure $(\boldsymbol{\pi})$ : Internal pressure $(\pi)$ is the resultant of the forces of attraction and repulsion between the molecules in a liquid. The repulsive forces become prominent showing relatively lower values of internal pressure. But the concentra-

TABLE-4

VALUES OF VARIATION MOLAR VOLUMES $\left(\mathrm{V}_{\mathrm{m}}{ }^{\mathrm{E}}\right)$, DEVIATION IN ADIABATIC

\begin{tabular}{|c|c|c|c|c|c|c|c|c|c|c|c|c|}
\hline \multirow{3}{*}{$\begin{array}{c}\text { Mole } \\
\text { fraction } \\
\text { X }\end{array}$} & \multicolumn{4}{|c|}{ Variation molar volumes } & \multicolumn{4}{|c|}{ Deviation in adiabatic compressibility } & \multicolumn{4}{|c|}{ Deviation in viscosity } \\
\hline & \multicolumn{2}{|c|}{$\begin{array}{c}\text { Temp. } 303.15 \mathrm{~K} \\
\mathrm{~A}=-0.3517 \\
\mathrm{~B}=1.5463 \\
\mathrm{C}=-1.0427 \\
\sigma=0.0137\end{array}$} & \multicolumn{2}{|c|}{$\begin{array}{c}\text { Temp. } 313.15 \mathrm{~K} \\
\mathrm{~A}=-0.5781 \\
B=1.9256 \\
\mathrm{C}=-0.6173 \\
\sigma=0.0118\end{array}$} & \multicolumn{2}{|c|}{ 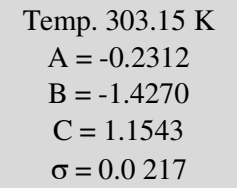 } & \multicolumn{2}{|c|}{$\begin{array}{c}\text { Temp. } 313.15 \mathrm{~K} \\
\mathrm{~A}=-0.2518 \\
\mathrm{~B}=-2.2784 \\
\mathrm{C}=1.2046 \\
\sigma=0.0217\end{array}$} & \multicolumn{2}{|c|}{$\begin{array}{c}\text { Temp. } 303.15 \mathrm{~K} \\
\mathrm{~A}=-0.0612 \\
B=1.5816 \\
\mathrm{C}=-0.3124 \\
\sigma=0.0135\end{array}$} & \multicolumn{2}{|c|}{$\begin{array}{c}\text { Temp. } 313.15 \mathrm{~K} \\
\mathrm{~A}=-0.0521 \\
\mathrm{~B}=1.2394 \\
\mathrm{C}=-1.0156 \\
\sigma=0.0215\end{array}$} \\
\hline & $\left(\mathrm{V}_{\mathrm{m}}^{\mathrm{E}}\right)$ & $\left(\mathrm{V}_{\mathrm{m}}^{\mathrm{E}}\right)_{\mathrm{cal}}$ & $\mathrm{V}_{\mathrm{m}}^{\mathrm{E}}$ & $\left(\mathrm{V}_{\mathrm{m}}^{\mathrm{E}}\right)_{\mathrm{cal}}$ & $\Delta \beta_{\mathrm{ad}}$ & $\left(\Delta \beta_{\mathrm{ad}}\right)_{\mathrm{cal}}$ & $\Delta \beta_{\mathrm{ad}}$ & $\left(\Delta \beta_{\text {ad }}\right)_{\text {cal }}$ & $\Delta \eta$ & $(\Delta \eta)_{\text {cal }}$ & $\Delta \eta$ & $(\Delta \eta)_{\mathrm{cal}}$ \\
\hline 0.0000 & 0.0000 & 0.0000 & 0.0000 & (1) 0000 & 0.0000 & 0.00 & 0.00 & & 0.00 & & 0.00 & 0.0000 \\
\hline 0.0937 & -1.0700 & & -1.4 & 00 & -1.08 & & -1 & & 0.0 & & & 300 \\
\hline 0.1887 & -2.0500 & -2.6 & -2.6100 & -2.6165 & -2.1100 & -2 & -2.9 & -2 . & 0.0 & & & 0.0556 \\
\hline 0.2851 & -2.8500 & -3.6000 & -3.6000 & -3.6120 & -3.0600 & -3.0695 & -3.9100 & -3.9180 & 0.0760 & 0.0768 & 0.0755 & 0.0759 \\
\hline 0.3829 & -3.4300 & -4.3107 & -4.3107 & -4.3167 & -3.8000 & -3.8150 & -4.5700 & -4.5755 & 0.0964 & 0.0966 & 0.0916 & 0.0919 \\
\hline 0.4820 & -3.6900 & -4.6462 & -4.6462 & -4.6462 & -4.2300 & -4.2300 & -4.8800 & -4.8800 & 0.1086 & 0.1086 & 0.0990 & 0.0990 \\
\hline 0.5826 & -3.3400 & -4.3727 & -4.3727 & -4.3697 & -4.0500 & -4.0585 & -4.6800 & -4.6850 & 0.0972 & 0.0969 & 0.0895 & 0.0885 \\
\hline 0.6847 & -2.7100 & -3.8000 & -3.8000 & -3.8120 & -3.4000 & -3.4150 & -4.1100 & -4.1250 & 0.0770 & 0.0759 & 0.0720 & 0.0727 \\
\hline 0.7882 & -1.8181 & -2.8400 & -2.8400 & -2.8420 & -2.5200 & -2.5265 & -3.1600 & -3.1680 & 0.0534 & 0.0544 & 0.0510 & 0.0518 \\
\hline 0.8933 & -0.9177 & -1.6000 & -1.6000 & -1.6000 & -1.4000 & -1.4000 & -1.9000 & -1.9000 & 0.0277 & 0.0277 & 0.0260 & 0.0260 \\
\hline 1.0000 & 0.0000 & 0.0000 & 0.0000 & 0.0000 & 0.0000 & 0.0000 & 0.0000 & 0.0000 & 0.0000 & 0.0000 & 0.0000 & 0.0000 \\
\hline
\end{tabular}
COMPRESSIBILITY $\left(\Delta \beta_{\mathrm{ad}}\right)$ AND DEVIATION IN VISCOSITY $(\Delta \eta)$ AT 303.15K AND $313.15 \mathrm{~K}$

TABLE-5

VALUES OF EXCESS INTERMOLECULAR FREE LENGTH $\left(\mathrm{L}_{\mathrm{f}}^{\mathrm{E}}\right)$, FREE VOLUME $\left(\mathrm{V}_{\mathrm{f}}\right)$,

\begin{tabular}{|c|c|c|c|c|c|c|c|c|c|c|}
\hline \multirow{2}{*}{$\begin{array}{l}\text { Mole } \\
\text { fraction } \\
\text { X }\end{array}$} & \multicolumn{2}{|c|}{$\begin{array}{c}\text { Temp. } 303.15 \mathrm{~K} \\
\mathrm{~A}=0.1151, \mathrm{~B}=-0.1211 \\
\mathrm{C}=-0.1213, \sigma=0.0025\end{array}$} & \multicolumn{2}{|c|}{$\begin{array}{c}\text { Temp. } 313.15 \mathrm{~K} \\
\mathrm{~A}=-0.1053, \mathrm{~B}=0.1124 \\
\mathrm{C}=-0.1123, \sigma=0.0022\end{array}$} & \multicolumn{3}{|c|}{ Temp. $303.15 \mathrm{~K}$} & \multicolumn{3}{|c|}{ Temp. $313.15 \mathrm{~K}$} \\
\hline & $\mathrm{L}_{\mathrm{f}}^{\mathrm{E}}$ & $\left(\mathrm{L}_{\mathrm{f}}^{\mathrm{E}}\right)_{\mathrm{cal}}$ & $\mathrm{L}_{\mathrm{f}}^{\mathrm{E}}$ & $\left(\mathrm{L}_{\mathrm{f}}^{\mathrm{E}}\right)_{\mathrm{cal}}$ & $\begin{array}{c}\mathrm{V}_{\mathrm{f}} \\
\left(\mathrm{cm}^{3} \mathrm{~mol}^{-1}\right)\end{array}$ & $\begin{array}{c}\pi \\
\left(\mathrm{N} / \mathrm{m}^{2}\right)\end{array}$ & $\mathrm{H}(\mathrm{J} / \mathrm{mol})$ & $\begin{array}{c}\mathrm{V}_{\mathrm{f}} \\
\left(\mathrm{cm}^{3} \mathrm{~mol}^{-1}\right)\end{array}$ & $\begin{array}{c}\pi \\
\left(\mathrm{N} / \mathrm{m}^{2}\right)\end{array}$ & $\mathrm{H}(\mathrm{J} / \mathrm{mol})$ \\
\hline 0.0000 & 0.0000 & 0.0000 & 0.0000 & 0.0000 & 2.8361 & 2559.95 & 236.21 & 3.1914 & 2450.77 & 227.58 \\
\hline 0.0937 & -0.0037 & -0.0037 & -0.0058 & -0.0058 & 3.1809 & 2471.49 & 226.99 & 3.5595 & 2375.39 & 218.88 \\
\hline 0.1887 & -0.0072 & -0.0075 & -0.0098 & -0.0095 & 3.6064 & 2375.83 & 217.43 & 4.0122 & 2289.97 & 209.97 \\
\hline 0.2851 & -0.0104 & -0.0106 & -0.0130 & -0.0132 & 4.1410 & 2271.10 & 207.54 & 4.5825 & 2194.79 & 200.69 \\
\hline 0.3829 & -0.0129 & -0.0131 & -0.0151 & -0.0153 & 4.8343 & 2155.42 & 197.17 & 5.3290 & 2086.54 & 190.87 \\
\hline 0.4820 & -0.0143 & -0.0143 & -0.0160 & -0.0160 & 5.7877 & 2023.67 & 185.97 & 6.3689 & 1960.14 & 180.13 \\
\hline 0.5826 & -0.0137 & -0.0139 & -0.0152 & -0.0155 & 7.2880 & 1859.96 & 172.87 & 7.9783 & 1804.69 & 167.73 \\
\hline 0.6847 & -0.0114 & -0.0120 & -0.0133 & -0.0131 & 9.6566 & 1677.42 & 158.14 & 10.5294 & 1629.50 & 153.65 \\
\hline 0.7882 & -0.0084 & -0.0085 & -0.0101 & -0.0104 & 13.7289 & 1475.09 & 141.43 & 14.9198 & 1433.08 & 137.64 \\
\hline 0.8933 & -0.0046 & -0.0046 & -0.0060 & -0.0060 & 21.7976 & 1250.34 & 121.91 & 23.7883 & 1209.60 & 118.65 \\
\hline 1.0000 & 0.0000 & 0.0000 & 0.0000 & 0.0000 & 42.9102 & 986.54 & 97.82 & 47.2383 & 946.24 & 95.20 \\
\hline
\end{tabular}
INTERNAL PRESSURE $(\pi)$ AND ENTHALPY $(H)$ AT 303.15 K AND $313.15 \mathrm{~K}$ 
tions where only one of the components is in large ratio, the internal pressure values are relatively higher predicting greater forces of attraction between the molecules. Internal pressure maximum, when the intermolecular association is strongest. Variation of internal pressure in the binary system at two temperatures is shown in Table-6.

The ratio can be molalities instead of mole fractions. As internal pressure is known to be an inverse function of free volume, the trend of the plots of free volume confirms the same. It is suggested that the behavior of internal pressure at different temperatures and concentrations may follow a specific mathematical function. A plot between the values of $\log \pi$ and $\log$ $\left(1 / \mathrm{V}_{\mathrm{f}}\right)$ resulted in a family of parallel straight lines with slope $\mathrm{x}$. The decrease in free volume and increase in internal pressure with increase in ethyl acetate in ethyl acetate $+n$-butanol binary liquid mixture at two different temperatures suggests the close packing of the molecules inside the shield, which may be brought about by the increasing magnitude of interactions.

When $n$-butanol is added to ethyl acetate it results in considerable decrease in intermolecular spaces between the molecules as suggested by Jacobson [21]. This contributes to increase in free volume and hence the decrease in the internal pressure and enthalpy giving raise to the negative $\mathrm{V}_{\mathrm{f}}^{\mathrm{E}}$ and positive $\pi^{\mathrm{E}}$ and $\mathrm{H}^{\mathrm{E}}$ values as its dilution causes disruption of the aromatic $\mathrm{C}-\mathrm{H}$ bond stretching.

Enthalpy: The values in Table- 6 shows that the decrease of enthalpy with increase in mole fraction of ethyl acetate.
Excess parameters: Excess values of internal pressure and enthalpy $\left(\pi^{\mathrm{E}}\right.$ and $\left.\mathrm{H}^{\mathrm{E}}\right)$ are shown in Table-6, which indicate that first the graph increase, attain maximum value at 0.5 and 0.6 mole fraction of ethyl acetate respectively, then decrease with further increase in its concentration, which indicate the strong intermolecular interaction between component molecules. The negative deviation of magnitude in $\mathrm{V}_{\mathrm{f}}^{\mathrm{E}}$ and positive values of $\pi^{\mathrm{E}}$ and $\mathrm{H}^{\mathrm{E}}$ indicate the presence of strong interaction between the hetero molecules of the mixture. Data presented in Tables 6-8 also indicate clearly that the increase in temperature cause variation in the experimental values of all the excess thermodynamic properties as the local structure of the liquids are destroyed, thus affecting their intermolecular free length and kinetic energy. In the binary mixture of ethyl acetate $+n$-butanol system, the excess values of $\pi^{\mathrm{E}}$ and $\mathrm{H}^{\mathrm{E}}$ show positive, thus suggesting strong interaction between the mixing components of molecules. The variation of excess internal pressure $\left(\pi^{\mathrm{E}}\right)$ is entirely positive. From Tables $6-8, \mathrm{H}^{\mathrm{E}}$ values are positive for ethyl acetate $+n$-butanol, excess enthalpies being positive suggests that the strong dipole-dipole interactions between the unlike molecules. The positive values of the excess enthalpies $\left(\mathrm{H}^{\mathrm{E}}\right)$ indicate that the breaking of the interactions existing in the pure compounds, especially the strong interactions existing between ethyl acetate molecules, is the main source of the energetic behaviour. In general, the excess enthalpies are positive when the interactions between unlike molecules are stronger than the interaction between like molecules, while

TABLE-6

VARIATION OF EXCESS FREE VOLUME, EXCESS INTERNAL PRESSURE EXCESS ENTHALPYAND EXCESS GIBB'S FREE ENERGY AT 303.15 K AND $313.15 \mathrm{~K}$

\begin{tabular}{|c|c|c|c|c|c|c|c|c|}
\hline \multirow{2}{*}{$\begin{array}{c}\text { Mole } \\
\text { fraction X }\end{array}$} & \multicolumn{4}{|c|}{ Temperature $303.15 \mathrm{~K}$} & \multicolumn{4}{|c|}{ Temperature $313.15 \mathrm{~K}$} \\
\hline & $\mathrm{V}_{\mathrm{f}}^{\mathrm{E}}\left(\mathrm{cm}^{3} \mathrm{~mol}^{-1}\right)$ & $\pi^{\mathrm{E}}\left(\mathrm{N} / \mathrm{m}^{2}\right)$ & $\mathrm{H}^{\mathrm{E}}(\mathrm{J} / \mathrm{mol})$ & $\mathrm{G}^{\mathrm{E}}(\mathrm{cal} / \mathrm{mol})$ & $\mathrm{V}_{\mathrm{f}}^{\mathrm{E}}\left(\mathrm{cm}^{3} \mathrm{~mol}^{-1}\right)$ & $\pi^{\mathrm{E}}\left(\mathrm{N} / \mathrm{m}^{2}\right)$ & $\mathrm{H}^{\mathrm{E}}(\mathrm{J} / \mathrm{mol})$ & $\mathrm{G}^{\mathrm{E}}(\mathrm{cal} / \mathrm{mol})$ \\
\hline 0.0000 & 0.0000 & 0.00 & 0.0000 & 0.00 & 0.0000 & 0.00 & 0.0000 & 0.00 \\
\hline 0.0937 & -3.4103 & 58.98 & 3.7511 & 50.10 & -3.7594 & 65.60 & 3.7064 & 51.67 \\
\hline 0.1887 & -6.7929 & 112.83 & 7.3420 & 97.92 & -7.4922 & 123.15 & 7.3766 & 101.00 \\
\hline 0.2851 & -10.1204 & 159.74 & 10.7851 & 143.51 & -11.1669 & 172.97 & 10.8517 & 147.18 \\
\hline 0.3829 & -13.3444 & 197.86 & 13.9425 & 185.26 & -14.7260 & 211.79 & 13.9710 & 189.13 \\
\hline 0.4820 & -16.3647 & 222.12 & 16.4683 & 220.36 & -18.0537 & 234.57 & 16.3629 & 223.80 \\
\hline 0.5826 & -18.8956 & 216.69 & 17.2848 & 240.39 & -20.8751 & 230.47 & 17.2763 & 244.82 \\
\hline 0.6847 & -20.6170 & 194.74 & 16.6794 & 242.41 & -22.8196 & 208.83 & 16.7096 & 247.43 \\
\hline 0.7882 & -20.6950 & 155.35 & 14.3045 & 219.25 & -22.9908 & 168.23 & 14.4090 & 224.59 \\
\hline 0.8933 & -16.8380 & 95.97 & 9.3315 & 152.44 & -18.7516 & 102.87 & 9.3294 & 155.96 \\
\hline 1.0000 & 0.0000 & 0.00 & 0.0000 & 0.00 & 0.0000 & 0.00 & 0.0000 & 0.00 \\
\hline
\end{tabular}

TABLE-7

VALUES OF EXCESS FREE VOLUMES $\left(\mathrm{V}_{\mathrm{f}}^{\mathrm{E}}\right)$ AND EXCESS INTERNAL PRESSURES $\left(\pi^{\mathrm{E}}\right)$ AT $303.15 \mathrm{~K}$ AND $313.15 \mathrm{~K}$

\begin{tabular}{|c|c|c|c|c|c|c|c|c|}
\hline \multirow[t]{2}{*}{$\begin{array}{c}\text { Mole } \\
\text { fraction X }\end{array}$} & \multicolumn{2}{|c|}{$\begin{array}{c}\text { Temp. } 303.15 \mathrm{~K} \\
\mathrm{~A}=-14.4783, \mathrm{~B}=-10.0561 \\
\mathrm{C}=-6.521, \sigma=0.4356\end{array}$} & \multicolumn{2}{|c|}{$\begin{array}{c}\text { Temp. } 313.15 \mathrm{~K} \\
\mathrm{~A}=-17.5812, \mathrm{~B}=-14.5632 \\
\mathrm{C}=-5.0256, \sigma=0.3256\end{array}$} & \multicolumn{2}{|c|}{$\begin{array}{c}\text { Temp. } 303.15 \mathrm{~K} \\
\mathrm{~A}=-15.4312, \mathrm{~B}=-36.4516 \\
\mathrm{C}=13.7589, \sigma=0.4526\end{array}$} & \multicolumn{2}{|c|}{$\begin{array}{c}\text { Temp. } 313.15 \mathrm{~K} \\
\mathrm{~A}=14.463, \mathrm{~B}=25.6321 \\
\mathrm{C}=-37.44, \sigma=0.9856\end{array}$} \\
\hline & $\mathrm{V}_{\mathrm{f}}^{\mathrm{E}}$ & $\left(\mathrm{V}_{\mathrm{f}}^{\mathrm{E}}\right)_{\mathrm{cal}}$ & $\mathrm{V}_{\mathrm{f}}^{\mathrm{E}}$ & $\left(\mathrm{V}_{\mathrm{f}}^{\mathrm{E}}\right)_{\mathrm{cal}}$ & $\pi^{\mathrm{E}}$ & $\left(\pi^{\mathrm{E}}\right)_{\mathrm{cal}}$ & $\pi^{\mathrm{E}}$ & $\left(\pi^{\mathrm{E}}\right)_{\mathrm{cal}}$ \\
\hline 0.0000 & 0.0000 & 0.0000 & 0.0000 & 0.0000 & 0.00 & 0.00 & 0.00 & 0.00 \\
\hline 0.0937 & -3.4103 & -3.4103 & -3.7594 & -3.7594 & 58.98 & 58.98 & 65.60 & 65.60 \\
\hline 0.1887 & -6.7929 & -6.7927 & -7.4922 & -7.4851 & 112.83 & 112.73 & 123.15 & 123.28 \\
\hline 0.2851 & -10.1204 & -10.1524 & -11.1669 & -11.1754 & 159.74 & 159.52 & 172.97 & 172.77 \\
\hline 0.3829 & -13.3444 & -13.3574 & -14.7260 & -14.7356 & 197.86 & 197.66 & 211.79 & 211.59 \\
\hline 0.4820 & -16.3647 & -16.3647 & -18.0537 & -18.0537 & 222.12 & 222.12 & 234.57 & 234.57 \\
\hline 0.5826 & -18.8956 & -18.8452 & -20.8751 & -20.8521 & 216.69 & 216.74 & 230.47 & 230.52 \\
\hline 0.6847 & -20.6170 & -20.6895 & -22.8196 & -22.8056 & 194.74 & 194.72 & 208.83 & 208.47 \\
\hline 0.7882 & -20.6950 & -20.6978 & -22.9908 & -22.9745 & 155.35 & 155.45 & 168.23 & 168.56 \\
\hline 0.8933 & -16.8380 & -16.8380 & -18.7516 & -18.7516 & 95.97 & 95.97 & 102.87 & 102.87 \\
\hline 1.0000 & 0.0000 & 0.0000 & 0.0000 & 0.0000 & 0.00 & 0.00 & 0.00 & 0.00 \\
\hline
\end{tabular}


TABLE-8

VALUES OF EXCESS ENTHALPY $\left(\mathrm{H}^{\mathrm{E}}\right)$ AND EXCESS GIBB'S FREE ENERGY $\left(\mathrm{G}^{\mathrm{E}}\right)$ AT $303.15 \mathrm{~K}$ AND $313.15 \mathrm{~K}$

\begin{tabular}{|c|c|c|c|c|c|c|c|c|}
\hline \multirow[t]{2}{*}{$\begin{array}{c}\text { Mole } \\
\text { fraction X }\end{array}$} & \multicolumn{2}{|c|}{$\begin{array}{c}\text { Temp. } 303.15 \mathrm{~K} \\
\mathrm{~A}=-11.658, \mathrm{~B}=-11.9856 \\
\mathrm{C}=-7.4521, \sigma=0.84521\end{array}$} & \multicolumn{2}{|c|}{$\begin{array}{c}\text { Temp. } 313.15 \mathrm{~K} \\
\mathrm{~A}=-21.4256, \mathrm{~B}=-13.5623 \\
\mathrm{C}=-7.5689, \sigma=0.7854\end{array}$} & \multicolumn{2}{|c|}{$\begin{array}{c}\text { Temp. } 303.15 \mathrm{~K} \\
\mathrm{~A}=-44.2646, \mathrm{~B}=24.3256 \\
\mathrm{C}=16.4523, \sigma=2.6785\end{array}$} & \multicolumn{2}{|c|}{$\begin{array}{c}\text { Temp. } 313.15 \mathrm{~K} \\
\mathrm{~A}=-48.2423, \mathrm{~B}=14.0754 \\
\mathrm{C}=-34.5877, \sigma=1.5623\end{array}$} \\
\hline & $\mathrm{H}^{\mathrm{E}}$ & $\left(\mathrm{H}^{\mathrm{E}}\right)_{\mathrm{cal}}$ & $\mathrm{H}^{\mathrm{E}}$ & $\left(\mathrm{H}^{\mathrm{E}}\right)_{\mathrm{cal}}$ & $\mathrm{G}^{\mathrm{E}}$ & $\left(\mathrm{G}^{\mathrm{E}}\right)_{\mathrm{cal}}$ & $\mathrm{G}^{\mathrm{E}}$ & $\left(\mathrm{G}^{\mathrm{E}}\right)_{\mathrm{cal}}$ \\
\hline 0.0000 & 0.0000 & 0.0000 & 0.0000 & 0.0000 & 0.00 & 0.00 & 0.00 & 0.00 \\
\hline 0.0937 & 3.7511 & 3.7511 & 3.7064 & 3.7064 & 50.10 & 50.10 & 51.67 & 51.67 \\
\hline 0.1887 & 7.3420 & 7.3556 & 7.3766 & 7.3255 & 97.92 & 97.85 & 101.00 & 101.12 \\
\hline 0.2851 & 10.7851 & 10.7958 & 10.8517 & 10.7452 & 143.51 & 143.42 & 147.18 & 147.17 \\
\hline 0.3829 & 13.9425 & 13.9148 & 13.9710 & 13.8452 & 185.26 & 185.56 & 189.13 & 189.23 \\
\hline 0.4820 & 16.4683 & 16.4683 & 16.3629 & 16.3629 & 220.36 & 220.36 & 223.80 & 223.80 \\
\hline 0.5826 & 17.2848 & 17.2589 & 17.2763 & 17.3568 & 240.39 & 240.45 & 244.82 & 244.78 \\
\hline 0.6847 & 16.6794 & 16.6653 & 16.7096 & 16.5546 & 242.41 & 242.24 & 247.43 & 247.55 \\
\hline 0.7882 & 14.3045 & 14.4512 & 14.4090 & 14.4856 & 219.25 & 219.63 & 224.59 & 224.65 \\
\hline 0.8933 & 9.3315 & 9.3315 & 9.3294 & 9.3294 & 152.44 & 152.44 & 155.96 & 155.96 \\
\hline 1.0000 & 0.0000 & 0.0000 & 0.0000 & 0.0000 & 0.00 & 0.00 & 0.00 & 0.00 \\
\hline
\end{tabular}

positive enthalpies are shown when the interaction between like molecules are stronger. The experimental results of the excess enthalpies indicate that the dipole-dipole interaction between ethyl acetate and alcohols are stronger.

Excess free volume: The values shown in Table-7 shows the variation of excess free volume in the binary system which is negative in the entire region.

Excess Gibbs free energy: Perusal of sign and magnitude of the parameters in Table-8, we found the strength of molecular interaction in the systems behave in the expected way. We also observed that $\mathrm{G}^{\mathrm{E}}$ is positive for the binary system at the two temperatures. Positive $G^{\mathrm{E}}$ is indicative of strong molecular interaction $[22,23]$. Several attempts have been made by various workers [24-28] relate $\mathrm{G}^{\mathrm{E}}$ to chemical interaction. However, $G^{\mathrm{E}}$ and $\eta^{\mathrm{E}}$ are affected by different contributions where relative significance appears to vary with the chemical nature and the type of interacting molecules. Hence, a conclusion can be drawn that chemical forces are dominating over the physical forces in all the systems [29].

The excess energies of activation to the mixtures of ethyl acetate with alcohols are positive values. The $\Delta \mathrm{G}^{\mathrm{E}}$ have local maxima at mole fraction about 0.5 for the system. The reason may be that the extent of interactions of alcohol molecules is a strong function of the composition in the mixtures, especially in the range dilute with respect to the associating component ethyl acetate. The values of $\Delta \mathrm{G}^{\mathrm{E}}$ are found to be positive over the entire composition range. Like $\Delta \eta$, the negative $\Delta \mathrm{G}^{\mathrm{E}}$ values are also indicative of the dominance of strong forces in these mixtures. Excess free volume, excess internal pressure, excess enthalpy and excess Gibb's free energy of activation of viscous flow, excess molar volume, excess intermolecular free length, deviation in adiabatic compressibility and deviation in viscosity were calculated at different temperatures over the whole composition range and fitted to the Redlich-Kister equation to test the quality of the experimental values. Estimated coefficients and standard deviation values are also presented. The results of the excess values indicate that the agreement between the experimental and theoretical values of the excess values is satisfactory and are depicted in Tables 7 and 8 . The negative values of excess free volume, excess molar volume, excess intermolecular free length, deviation in adiabatic compressibility and positive values of excess internal pressure, excess enthalpy excess,
Gibbs free energy of activation and deviation in viscosity hint to the presence of strong dipole-dipole interactions between the component molecules in the liquid mixtures studied and the inherent nature of ethyl acetate predominant the existing strong interactions. From the ultrasonic velocity curves, the variation of ultrasonic velocity with the mole fraction of ethyl acetate at two different temperatures for ethyl acetate $+n$-butanol system indicates that the ultrasonic velocity non-linearly varies with mole fraction and decreases with increasing temperatures at any particular concentration.

Estimation of the variation of theoretical velocities using Nomoto Relation (Nom) and Van Dael Vangeel ideal mixing relation (Van) at 303.15 and $313.15 \mathrm{~K}$ : The experimental values along with the values calculated theoretically using the relations of Nomoto and Van Dael ideal mixing for ethyl acetate $+n$-butanol at 303.15 and $313.15 \mathrm{~K}$ are given in Table-9. It shows that there is good agreement between experimental and theoretical values calculated by Van Dael ideal mixing and Nomoto relations. Here Nomoto's relation provides the best result than the result of ideal mixing relation $[30,31]$. It is observed that the minimum percentage of deviation is exhibited by Nomoto relation and followed by Van Deal's relation. This is in good agreement with the conclusions drawn by others [32-34]. Data revealed that the sound speed computed from Nomoto's relation exhibits more satisfactory agreement with the experimental values in the temperatures range of 303.15 and $313.15 \mathrm{~K}$. The ratio $\mathrm{U}_{\text {exp }}^{2} / \mathrm{U}^{2}$ imx is used as an important tool to measure the non-ideality in the mixtures, especially in these cases where the properties other than sound velocity are not known.

\section{Conclusion}

The results of these studies may be used for examining the suitability of these mixtures for practical applications such as in paints, varnishes, printing ink industries, biomedical engineering, textile industry, leather industry and pharmaceutical industry. This study can be taken as a reference and thermodynamic properties of many other binary mixtures can be studied at different temperatures.

\section{ACKNOWLEDGEMENTS}

The authors are grateful to The Management of CMR College of Engineering \& Technology, Hyderabad, India for support during the research work. 
TABLE-9

NOMOTO RELATION (NOM) \& VANDAEL VANGEEL IDEAL MIXING

RELATION (VAN) AT TWO TEMPERATURES 303.15 K AND 313.15 K

\begin{tabular}{|c|c|c|c|c|c|c|c|c|c|c|c|c|}
\hline \multirow{2}{*}{$\begin{array}{l}\text { Mole } \\
\text { fraction } \\
\quad \mathrm{X}\end{array}$} & \multicolumn{6}{|c|}{ Temperature $303.15 \mathrm{~K}$} & \multicolumn{6}{|c|}{ Temperature $313.15 \mathrm{~K}$} \\
\hline & $\begin{array}{c}U_{\text {exp }} \\
(\mathrm{m} / \mathrm{s})\end{array}$ & $\mathrm{U}_{\text {Nomoto }}$ & $\mathrm{U}_{\mathrm{idmx}}$ & $\% \mathrm{U}_{\mathrm{No}}$ & $\% \mathrm{U}_{\mathrm{imx}}$ & $\mathrm{U}_{\text {exp }}^{2} / \mathrm{U}^{2}{ }_{\mathrm{imx}}$ & $\begin{array}{c}U_{\text {exp }} \\
(\mathrm{m} / \mathrm{s})\end{array}$ & $\mathrm{U}_{\text {Nomoto }}$ & $\mathrm{U}_{\mathrm{idmx}}$ & $\% \mathrm{U}_{\mathrm{No}}$ & $\% \mathrm{U}_{\mathrm{imx}}$ & $\mathrm{U}_{\text {exp }}^{2} / \mathrm{U}^{2}{ }_{\mathrm{imx}}$ \\
\hline 0.0000 & 1222 & 22.00 & 1222.00 & 0.0000 & 0.0000 & 1.0000 & 1211.00 & 1211.00 & 1211.00 & 0.0000 & 0.0000 & 1.0000 \\
\hline 0.0937 & 1211.62 & 1211.10 & 1210.84 & -0.0433 & -0.0650 & 1.0013 & 1199.28 & 1197.16 & 1196.76 & -0.1767 & -0.2101 & 1.0042 \\
\hline 0.1887 & 1201.59 & 1200.26 & 1199.80 & -0.1107 & -0.1489 & 1.0030 & 1185.76 & 1183.56 & 1182.70 & -0.1851 & -0.2580 & 1.0052 \\
\hline 0.2851 & 1192.27 & 1189.49 & 1188.90 & -0.2332 & -0.2828 & 1.0057 & 1171.64 & 1170.09 & 1168.80 & -0.1327 & -0.2421 & 1.0049 \\
\hline 0.3829 & 1182.97 & & 1178.12 & -0.3534 & -0.4095 & 1.0082 & 1157.49 & 115 & 1155.08 & & -0.2080 & 1.0042 \\
\hline 0.4820 & 1173.59 & 1168 & $116^{\circ}$ & -0.4643 & -0.5221 & 1.0105 & 1143.54 & 1143.50 & 1141.51 & -0.0 & -0.1771 & 1.0036 \\
\hline 0.5826 & 1163.87 & 1157.57 & 1156.93 & -0.5414 & -0.5963 & 1.0120 & 1130.24 & 1130.38 & 1128.11 & 0.0126 & -0.1888 & 1.0038 \\
\hline 0.6847 & 1152.75 & 1147.06 & 1146.51 & -0.4936 & -0.5412 & 1.0109 & 1116.65 & 1117.39 & 1114.86 & 0.0660 & -0.1607 & 1.0032 \\
\hline 0.7882 & 1141.82 & 1136.61 & 1136.20 & -0.4565 & -0.4924 & 1.0099 & 1103.30 & 1104.51 & 1101.76 & 0.1104 & -0.1393 & 1.0028 \\
\hline 0.8933 & 1129.56 & 1126.22 & 1126.00 & -0.2954 & -0.3154 & 1.0063 & 1090.01 & 1091.76 & 1088.81 & 0.1599 & -0.1106 & 1.0022 \\
\hline 1.0000 & 1115.90 & 1115.90 & 1115.90 & 0.0000 & 0.0000 & 1.0000 & 1076.00 & 1076.00 & 1076.00 & 0.0000 & 0.0000 & 1.0000 \\
\hline
\end{tabular}

\section{CONFLICT OF INTEREST}

The authors declare that there is no conflict of interests regarding the publication of this article.

\section{REFERENCES}

1. O. Müller and J. Winkelmann, Phys. Rev. E, 59, 2026 (1999); https://doi.org/10.1103/PhysRevE.59.2026.

2. A. Bagheri and S.A. Mirbakhshi, Phys. Chem. Liq., 54, 529 (2016); https://doi.org/10.1080/00319104.2015.1121783.

3. D. Belmonte, C. Gatti, G. Ottonello, P. Richet and M. Vetuschi Zuccolini, J. Phys. Chem. A, 120, 8881 (2016); https://doi.org/10.1021/acs.jpca.6b08676.

4. Z. Chen, Y. Huo, P. Long, H. Shen and J.M. Lee, Phys. Chem. Chem. Phys., 19, 5389 (2017); https://doi.org/10.1039/c6cp08876g.

5. P. Prabhu and A.R. Venis, Asian J. Chem., 30, 1759 (2018); https://doi.org/10.14233/ajchem.2018.21292.

6. R.H. Perry and D.W. Green, Perry's Chemical Engineers' Handbook McGraw-Hill: New York, edn 7, pp. 13-20 (1997).

7. J.H. Hildebrand and R.L. Scott, Regular Solutions, Prentice-Hall: New York, pp. 104-115 (1962)

8. G. Scatchard, Chem. Rev., 8, 321 (1931); https://doi.org/10.1021/cr60030a010.

9. J.H. Hildebrand and C.A. Jenks, J. Am. Chem. Soc., 42, 2080 (1920); https://doi.org/10.1021/ja01455a015.

10. J.H. Hildebrand, J. Am. Chem. Soc., 51, 66 (1929); https://doi.org/10.1021/ja01376a009.

11. J.H. Hildebrand, Phys. Rev., 34, 984 (1929); https://doi.org/10.1103/PhysRev.34.984.

12. J.H. Hildebrand, Proc. Nat. Acad. Sci., 13, 267 (1927); https://doi.org/10.1073/pnas.13.5.267.

13. O. Redlich and A.T. Kister, Ind. Eng. Chem., 40, 345 (1948); https://doi.org/10.1021/ie50458a036.

14. M.R. Rao, J. Chem. Phys., 9, 682 (1941); https://doi.org/10.1063/1.1750976.

15. T. Jacobson, Phys. Rev. Lett., 75, 1260 (1995); https://doi.org/10.1103/PhysRevLett.75.1260.

16. R. Padmanaban, K. Venkatramanan, S. Girivel, K. Kasthuri, A. Usharani, A. Gayathri and R. Vellaichamy, ed.: J. Ebenezar, Mathematical and Experimental Analysis of Ultrasound Velocity and Refractive Index in Binary Mixtures of Pharmaceutically Important Polymer-PEG 600; In: Recent Trends in Materials Science and Applications, Springer International Publishing: Switzerland, pp: 709-722 (2017).
17. V.S. Rao, T.V. Krishna, T.M. Mohan and P.M. Rao, J. Solution Chem., 46, 281 (2017);

https://doi.org/10.1007/s10953-017-0578-y.

18. A. Saini, A. Harshvardhan and R. Dey, Indian J. Chem., 51A, 21 (2012).

19. J.O. Hirschfelder, Hirschfelder, J.O., Molecular Theory of Gases and Liquids, John Wiley, New York, p. 29 \& 286 (1959).

20. J.O. Hirschfelder, J. Chem. Educ., 16, 540 (1939); https://doi.org/10.1021/ed016p540.

21. A. Schmidt, M. Zad, W.E. Acree Jr. and M.H. Abraham, Phys. Chem. Liq., 54, 313 (2016); https://doi.org/10.1080/00319104.2015.1084882.

22. R. Sharma, R.C. Thakur and B. Saini, Asian J. Chem., 28, 2331 (2016); https://doi.org/10.14233/ajchem.2016.20010.

23. I.A. Sedov, T.I. Magsumov, M.A. Stolov and B.N. Solomonov, Thermochim. Acta, 623, 9 (2016); https://doi.org/10.1016/j.tca.2015.11.010.

24. J.P. Singh and R. Sharma, Int. J. Eng. Res. Dev., 5, 48 (2013).

25. J. Tong, Y. Qu, K. Li, T.-F. Chen, J. Tong and J.-Z. Yang, J. Chem. Thermodyn., 97, 362 (2016); https://doi.org/10.1016/j.jct.2016.02.001.

26. Y. Xu, H. Zhu and L. Yang, J. Chem. Eng. Data, 58, 2260 (2013); https://doi.org/10.1021/je400331r.

27. L. Venkatramana, R.L. Gardas, C.N. Rao, K. Sivakumar and K.D. Reddy, J. Sol. Chem., 44, 327 (2015); https://doi.org/10.1007/s10953-015-0309-1.

28. R.R. Naik, S.V. Bawankar, P.V. Tekade and O.A. Mahodaya, Russ. J. Phys. Chem. A, 89, 152 (2015); https://doi.org/10.1134/S0036024415010227.

29. R. Mehra and B.B. Malav, Arabian J. Chem., 10, S1894 (2017); https://doi.org/10.1016/j.arabjc.2013.07.018.

30. B. Kubíková, M. Boèa, J. Mlynáriková, Z. Netriová and Z. Vasková, J. Thermal Anal. Calorim., 125, 497 (2016); https://doi.org/10.1007/s10973-016-5324-y.

31. K. Saravanakumar, T.G. Lavanya and T.R. Kubendran, J. Eng. Thermophys., 25, 106 (2016); https://doi.org/10.1134/S1810232816020144.

32. Y. Wang, Q. Liu, L. Qiu, T. Wang, H. Yuan, J. Lin and S. Luo, Spectrochim. Acta A: Mol. Bimol. Spectrosc., 150, 902 (2015); https://doi.org/10.1016/j.saa.2015.06.027.

33. F. Chen, Z. Yang, Z. Chen, J. Hu, C. Chen and J. Cai, J. Mol. Liq., 209, 683 (2015); https://doi.org/10.1016/j.molliq.2015.06.041

34. R. Padmanaban, K. Venkatramanan, S. Girivel, K. Kasthuri, A. Usharani, A. Gayathri and R. Vellaichamy, Recent Trends Mater. Sci. Appl., 189, 709 (2017); https://doi.org/10.1007/978-3-319-44890-9 57. 